\title{
DESIGN OF AUTOMATIC ORGANIC WASTE CRUSHER USING ARDUINO MICROCONTROLLER
}

\author{
Mufidatul Islamiyah, Adriani Kala'lembang
}

\begin{abstract}
Organic waste is the residual daily activities of humans or natural processes in the form of solid or semi-solid in the form of organic or inorganic substances that are biodegradable or unraveled which are considered useless and disposed of in the environment. This organic waste can be used as fertilizer for plants if processed properly, therefore this waste can be used as fertilizer processing by destroying, so this study aims to create a tool that can destroy waste so that it is easy to process using an Arduino microcontroller, the design is done ranging from hardware to software. The way the device works is to detect the material to be destroyed, then the system will be active, the tool is designed a choice of time for the material to be destroyed so that the appliance will automatically die when the time expires and the choice of blade rotation speed from maximum, medium to minimum. From the experiments carried out the tool was able to destroy the material until smooth.
\end{abstract}

Index Terms-Organic Waste, Microcontroller Arduino, speed motors.

\section{INTRODUCTION}

$\mathrm{O}$ rganic waste is the residual daily activities of humans or natural processes in the form of solid or semi-solid in the form of organic or inorganic substances that are biodegradable or unraveled which are considered useless and disposed of in the environment. This organic waste can be used as fertilizing plants if treated properly [1].

This organic waste mostly comes from leaves, food scraps, animal waste. Organic waste has great potential to be reused into useful items and can have considerable economic value. There is a lot of trash from food scraps throughout the people's homes that is too much and will not be utilized so that the waste becomes useless and becomes a problem in the community because it causes odor and disease, therefore from these problems it encourages innovation to utilize waste as material your map is recycled and beneficial to the community. From the above problems it is necessary to design a tool that

Mufidatul Islamiyah, Lecturer in Informatics engineering of STMIK ASIA, Malang, Indonesia (+62 $8564916 \quad 8867$; email Mufidatu1014@gmail.com)

Adriani Kala'lembang Lecturer in Informatics engineering of STMIK ASIA, Malang, Indonesia (+62 8564916 8867; email Adriani.riny@gmail.com) is used as a destroyer of organic waste, the design of this tool uses a microcontroller, which is a technological breakthrough. The microcontroller is a driver on the basic digital rules so that the operation of the system becomes very easy to do in accordance with the system logic. The microcontroller is very easy to use because it does not use a lot of commands, the microcontroller provides additional facilities for memory and $\mathrm{I} / \mathrm{O}$ development that are tailored to the needs of the system, the price of a microcontroller is cheaper and easier to obtain.

\section{METHODOLOGY}

\section{A. Design System}

Design Analysis of the problem and the working principle of the tool is able to make a tool that smooths the rest of the trash so that the food waste does not subvert the flow of water flowing in the place of washing the cooking utensils, in this tool the shape of the tool is designed to resemble the workings of electronic devices namely blenders, after food waste mashed until the food is finished into liquid.

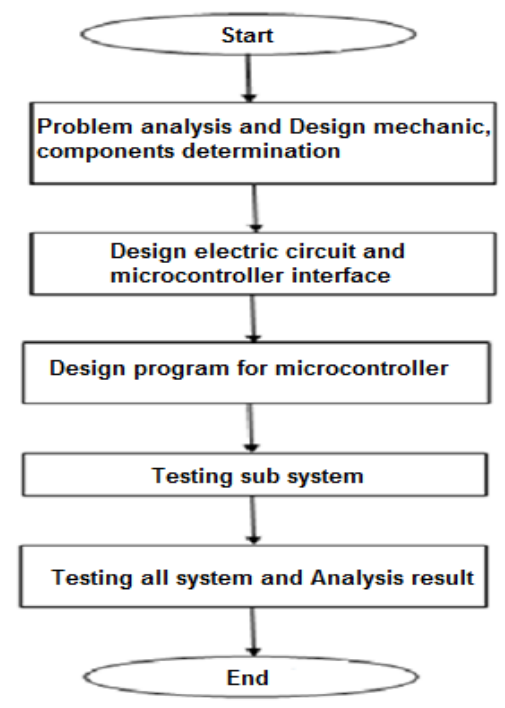

Fig. 1 Flowchart Methodology of Research

\section{B. Mechanic Design}

The scheme for the design of mechanical tools is shown in Figure 1. 


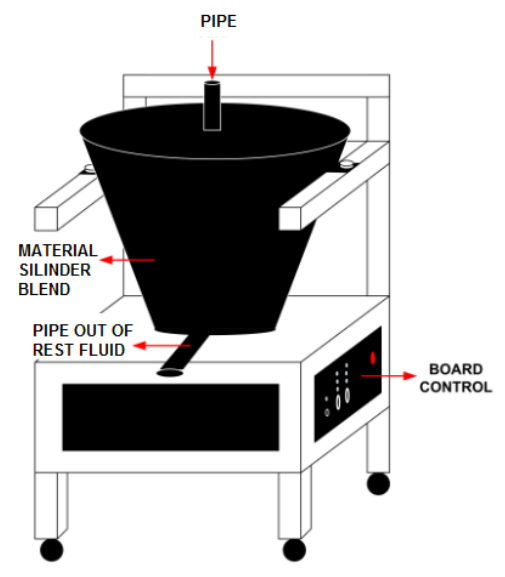

Fig. 2 Mechanic Design

The design of the tool uses the idea of how the electronic device blender works, the tool used has a box to store the material to be destroyed [2].

The motor will move the blade to destroy the material that has been inserted, for the motor made with maximum speed, medium to minimum, the tool is also made to work automatically so that a timer system is added as a timer so that power efficiency can be maintained.

\section{DESIGN SYSTEM}

\section{A. Design of Microcontroller}

The electrical circuit scheme consists of one microcontroller, $220 \mathrm{~V}$ and 5 Volt power supply for the power supply needed by the microcontroller, one switch to activate the device, a timer used to set the time of the active device in accordance with the user's wishes, the motor drive switch circuit to activate a knife for cutting the material on the tool, and a set of speed control for the blade movement according to the user's desire, so that the rough and smooth material of the knife rotation can be adjusted. The scheme is shown in Figure 3.

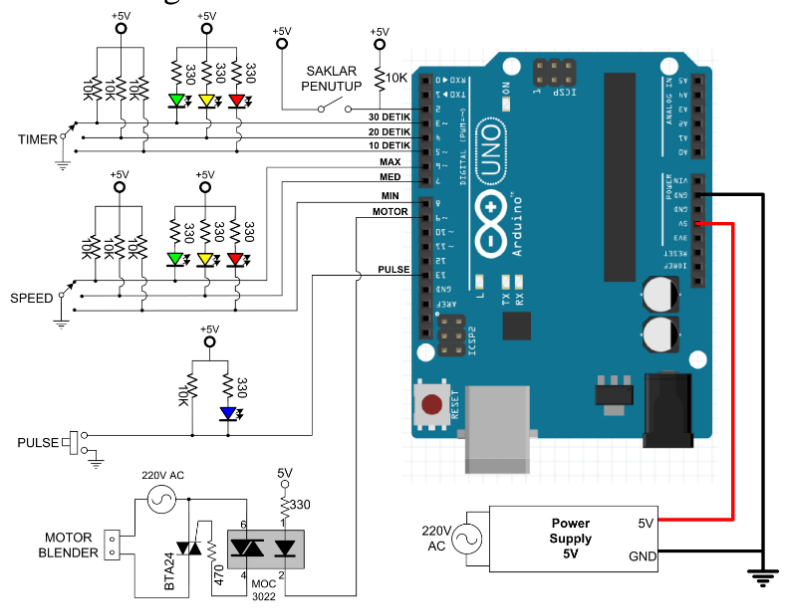

Fig. 3 Microcontroller Design

Microcontroller pins on the design of this tool are allocated as follows:

- The $5 \mathrm{~V}$ Powe pin is connected to a $5 \mathrm{~V}$ voltage on the power supply circuit.
- Pin 13 is connected to a series of pulses to regulate the reading of data on the microcontroller

- Pin 9 is connected to the circuit to activate the blade drive motor in the tool

- Pin 8.7.6 is connected to the motor speed control circuit for maximum, medium and low

- The 5,4,3 pin is connected to the timer circuit to set the active time of the tool at 10,20, and 30 seconds.

- The GND pin is connected GND to the power supply

\section{B. Design of Timer System}

The timer on this system uses a rotary encoder switch to select the desired time which is 10 seconds, 20 seconds, and 30 seconds. The digital pin that is used on the Arduino for the system on the timer is the 3 digital pin for the timer on for 30 seconds, the digital pin 4 for the timer on for 20 seconds, the digital pin 5 for the timer on for 10 seconds, if one of the digital pins is used for the timer gets a low signal from the rotary switch, then the activation on the timer starts [3]. The circuit scheme for timers is shown in Figure 4.

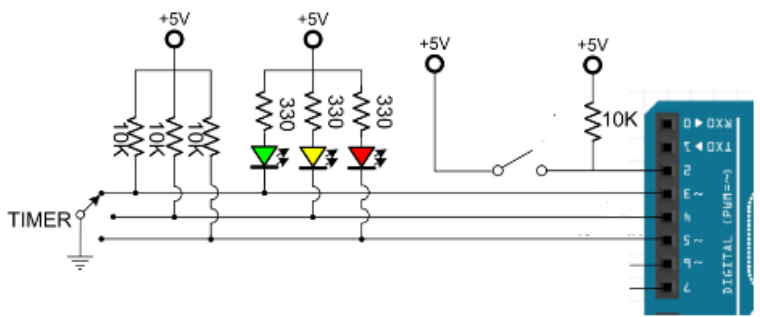

Fig. 4 Timer Circuit Design

\section{Design of Speed Motor}

Just like the working principle of a timer circuit, the system for selecting speed uses a rotary switch. The digital pin used in Arduino for system speed is a digital pin 6 for maximum speed, digital pin 7 for medium speed, digital pin 8 for minimum speed, if one of the digital pins used for speed gets a low signal from the rotary switch, then the speed selected will be active. The speed selector circuit is shown in Fig 5.

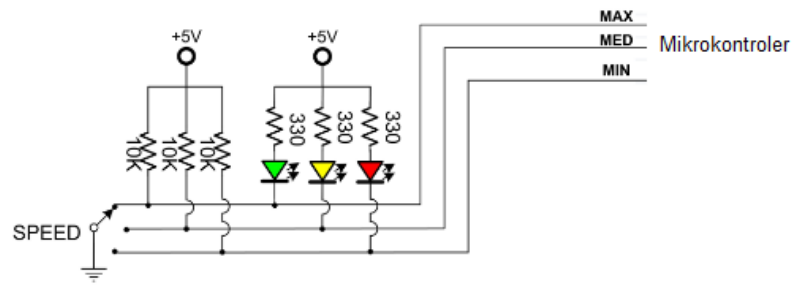

Fig. 5 Speed of Motor Circuit Design

\section{Design of Pulse Circuit}

This system is equipped with a pulse button whose function is to activate the blender when the pulse button is pressed. When pressed the 13 digital pin on the Arduino gets a low signal from the push button switch, and is used as a sign by Arduino to activate the blender[4]. The pulse circuit is shown in Fig 6. 


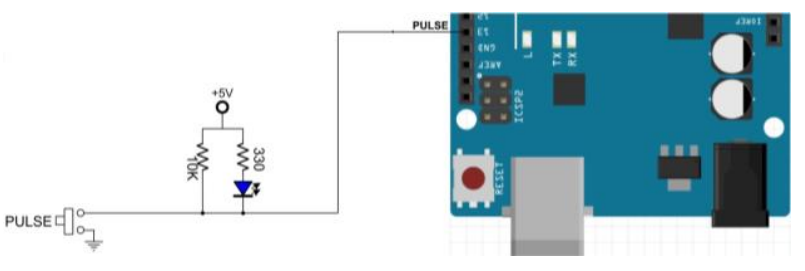

Fig. 6 Pulse Circuit Design

\section{E. Design of Motor System}

In the motor speed control circuit used Optocoupler or optoisolator is a semiconductor component composed of infrared LEDs (Light Emitting Diodes) and a photo triac that is used as a triac controller. Optoisolator is usually used as an interface between the control circuit with the power circuit (triac) and also as a safety control, because the LED and photo triac are not electrically connected, so if there is damage to the power circuit (triac) the controller circuit is not damaged. MOC 3022 is useful as an electrical switch to activate the $220 \mathrm{~V}$ voltage so that the motor can move [2].

The way the circuit works is when the microcontroller gives an active signal, the switch will channel the current so that the $220 \mathrm{~V}$ voltage can be applied to the motor so that the motor used to move the blade moves according to the commands of the microcontroller. Triac in MOC 3022 will be active if the LED in the MOC is lit. MOC 3022 is safe to use to regulate the $\mathrm{AC}$ control motor because the LED in MOC3022 is turned on by using a 5V voltage and the triac on MOC3022 can be passed by AC current[4]. pin 1 MOC3022 is connected to a $5 \mathrm{~V}$ voltage which is lit with a $330 \mathrm{ohm}$ resistor to limit the current entering the led. pin $2 \mathrm{MOC}$ is connected to Arduino 9 digital pin. The circuit will shown in Fig 7.

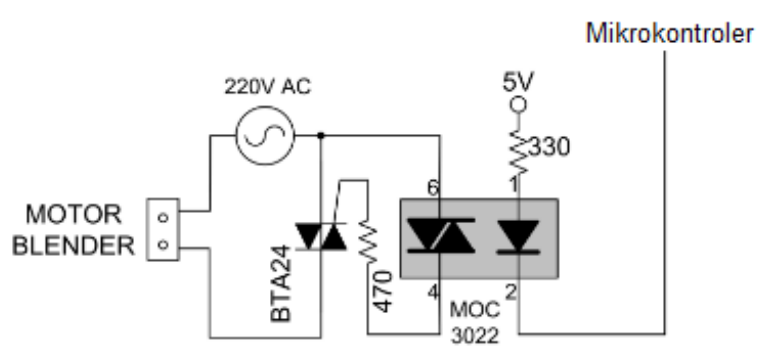

Fig. 7 Motor Circuit Design

The digital pin 9 on Arduino is a digital pin that can output a PWM signal that is used to adjust the LED on MOC3022. The brighter the LED light on MOC3022, the faster the AC motor rotates, and vice versa. In addition the MOC3022 circuit above also uses a triac BTA24 to control the AC motor. Use TRIAC BTA24 Because the triac output current at MOC3022 is too small to drive the AC motor. While the maximum current that can be passed on BTA24 is 25A (datasheet). When the output conditions on the 9 arduino digital pin emit a low signal, the LED on MOC3022 will turn on, and cause the AC current to pass through the MOC 3022 triac and activate the BTA24 triac, the blender motor will spin.
When the output condition on the 9 pin digital pin releases a high signal, the LED on MOC3022 will not turn on. This condition will cause the triac on MOC3022 to be inactive so that the triac BTA24 is not active so the motor blender is off.

\section{RESULT AND ANALYSIS}

\section{A. Result of System}

Based on the design that has been described, then the testing of the device that has been designed is carried out.

After entering the material to be processed, the system will be opened and the destruction process is carried out, for a long time the timer has been provided to make the device automatically inactive for 10,20 to 30 seconds. The crushing process of the tool is carried out by a knife that has been installed on a tool with maximum, medium to minimum speed capabilities. The results of the tool destruction are shown in the figure 7 .

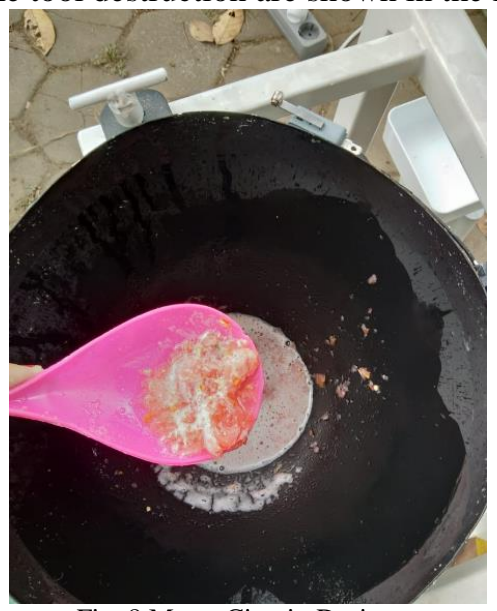

Fig. 8 Motor Circuit Design

From the results of the design, the purpose of the research is to create a tool that is capable of destroying food waste material which will be processed for fertilizer, the results of the tool are made just to destroy it, and the results will be further processed. So that when the tool is able to refine the food waste. The way the tool works is detecting the presence of garbage that is already in the material valve, then activating the tool timer and selecting the speed of the crushing blade in accordance with the material to be destroyed, the designed tool is made the choice of maximum, medium and minimum rotation. The system will shown in Figure 9.

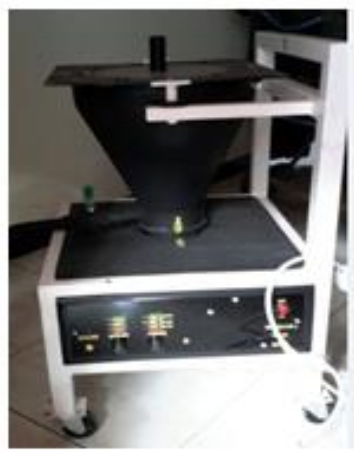

Fig. 9 Design Result 


\section{CONCLUSION}

The tool is designed to be able to destroy the tools until it is smooth specifically for the waste of kitchen cooking waste such as fruit skin, fruit and leftovers from home food.

For further research, it is necessary to design a destroyer that is capable of destroying hard materials so that a robust mechanical design is needed, in addition to the automatic side of the tool, it can be developed by designing a tool that is able to adjust the rotation speed based on rough and smooth material without having to arrange it in advance.

\section{REFERENCES}

[1] https://id.wikipedia.org/wiki/Sampah organik (10 maret 2016)

[2] Khurmi,R.S, \& Gupta, J.K. (2002). Machine Design, New Delhi: S.C Had \& Company LTD. Ram

[3] Radianto, Y., 2017, Pengendalian Jarak Jauh Menggunakan Mikrokontroler Arduino, Jakarta

[4] Wardhana, L.,2003, Mikrokontroler AVR Seri ATMe8535 Simulasi, Hardware, dan Aplikasi, ANDI : Yogyakarta. 